\title{
Editorial
}

\section{El mundo ha cambiado}

\author{
DOI 10.5377/alerta.v5i1.13209
}

Guillermo Schor-Landman

Universidad de Buenos Aires y Universidad Internacional de Valencia; Fundación Iberoamericana de Telemedicina, Buenos Aires, Argentina.

${ }^{*}$ Correspondencia

$\checkmark$ gschor@telemed.org.ar

(D) $0000-0002-3787-3628$

\section{Introducción}

Las tecnologías de la información y comunicaciones (TIC) y la pandemia COVID-19 han transformado la forma de vivir y convivir.

Las TIC han modificado hábitos, costumbres y prácticas, que han facilitado el acceso a servicios más modernos y eficientes en el nuevo escenario de la sociedad de la información y del conocimiento. Han impactado en el ámbito de la salud con soluciones tecnológicas para la investigación, los servicios médicos, la atención del paciente y la administración, gracias a la cantidad de datos que hoy son recolectados y pueden ser analizados de forma oportuna por medio de aplicaciones informáticas, especialmente con Inteligencia Artificial (IA).

La IA fue desarrollada en la década del 50, pero hasta hace pocos años se han creado los sensores capaces de recolectar la cantidad de datos que hoy por hoy se tienen al alcance. La pandemia por COVID-19, emergencia sanitaria global, ha derribado las barreras culturales que habían demorado el uso intensivo de las herramientas tecnológicas en el ámbito de la salud.

La necesidad de conocer, prevenir y dar una atención de calidad ha impuesto de forma natural la salud digital, definida por la Organización Mundial de la Salud (OMS) como el uso de TIC para la salud.

El expediente clínico electrónico, la teleconsulta, la receta electrónica y, sobre todo, la IA para la investigación y atención de la salud hoy son términos que ya resultan habituales.
Por los beneficios que brindan a la población, es obligación de los gobiernos informatizar la atención de la salud rápidamente; pero como toda creación del hombre siempre genera riesgos, y solo las mejores prácticas deberían mantenerse cuando se supere la pandemia, también es mandatorio que los gobiernos reglamenten a la brevedad la salud digital, especialmente la IA estableciendo los límites éticos a sus aplicaciones.

Pese a los importantes beneficios que brinda el desarrollo de la tecnología también existe una exposición al riesgo; que pueden ser sobre los derechos fundamentales y la seguridad de las personas por errores en su desarrollo, sesgos discriminatorios o por mala fe. Por ello, debe ser regulada especialmente en el buen uso de los datos y en la atribución de responsabilidad por daños.

La regulación no es prohibición. No debe ser un freno a la innovación, sino que debe establecer los límites que colaboren con el buen uso de la tecnología.

\section{Inteligencia artificial}

Es un término que engloba aquellos sistemas informáticos capaces de detectar su entorno, pensar, aprender y tomar decisiones; es decir, pueden trabajar de manera autónoma en función de los datos que reciben y sus objetivos definidos en algoritmos $^{1}$. La IA permite que las máquinas aprendan de la experiencia, se ajusten a nuevos contextos y actúen de forma similar a como lo haría un humano.

\section{ACCESO ABIERTO} The world has changed

Citación recomendada: Schor-Landman, G. El mundo ha cambiado. Alerta. 2022;5(1):3-5 DOI: 10.5377/ alerta.v5i1.13209

\section{Recibido:}

06 de enero de 2022

\section{Aceptado:}

18 de enero de 2022

\section{Publicado:}

27 de enero de 2022

\section{Contribución de autoría:}

GSL ${ }^{1}$. Revisión de la literatura y elaboración del manuscrito.

\section{Conflicto de intereses:}

El autor declara que no existe conflicto de interés. 
Se estima que la IA será tan trascendental como hace unas décadas fue el descubrimiento de internet, ya que todos los sectores productivos están siendo influenciados por esta tecnología: la salud, la agricultura, la industria, el comercio; los servicios, la educación, la cultura, el entretenimiento, etc.

Se espera también una reducción drástica de los años necesarios para que las naciones dupliquen el tamaño de sus economías, dependiendo de la capacidad de cada país para implementar la IA en su infraestructura².

No obstante, así como la IA puede ser una herramienta fundamental para el desarrollo, también puede ampliar las distancias entre países y personas. Por ello, la implementación de principios éticos es esencial y constituye uno de los elementos más relevantes.

\section{Ética de la inteligencia artificial}

Se define como una rama de la ética que analiza y evalúa los dilemas morales que se derivan del despliegue de esta tecnología en la sociedad. La adopción de aplicaciones capaces de tomar decisiones por sí mismas sigue planteando numerosas dudas a nivel ético. Las administraciones públicas deben anticipar y prevenir futuros daños potenciales, con una cultura de innovación responsable para el desarrollo e implementación de sistemas de IA justos, seguros y, consecuentemente, confiables.

\section{Potenciales riesgos}

Existen posibles riesgos asociados a la adopción de sistemas de IA como: la destrucción de puestos de trabajo, la manipulación, seguridad y vulnerabilidad de software y hardware, la intrusión a la privacidad, aumento de la brecha digital entre países y personas; la erosión de la sociedad civil a través de la manipulación de la información, entre otros.

En la programación de la IA pueden aparecer sesgos y es ahí donde la ética adquiere un papel crucial. Del mismo modo que cada persona tiene prejuicios, los programadores de las aplicaciones inteligentes también pueden tenerlos, aunque probablemente no se harán evidentes hasta que se acumulen varios errores en el sistema.

\section{Posibles soluciones}

Para que la IA resulte confiable y supere el desafío de los riesgos, se deben determinar los siguientes aspectos:

1. Ciclo de vida de la IA. Las etapas del ciclo de vida de estos sistemas van desde la investigación, la concep- ción y el desarrollo hasta el despliegue y la utilización, pasando por el mantenimiento, el funcionamiento, la comercialización, financiación, seguimiento y evaluación, validación, el fin de la utilización, el desmontaje y la terminación ${ }^{3}$.

2. Actores. Persona que participe en al menos una etapa del ciclo de vida del sistema de IA. Estos pueden ser investigadores, programadores, ingenieros, especialistas en datos, usuarios finales, empresas, universidades y entidades públicas y privadas, entre otros.

Es fundamental esta definición de los conceptos anteriores, para identificar claramente a los responsables, sean personas humanas o jurídicas, en caso de daños, a fin de generar la confianza que requiere el desarrollo de la IA.

3. Supervisión humana. Un requisito esencial para la fiabilidad es que, a lo largo de su ciclo de vida, los sistemas de IA estén sujetos a un seguimiento permanente por parte de los actores, usuarios, instituciones y gobiernos, según corresponda.

En los casos en que se entienda que las decisiones tienen un impacto irreversible o difícil de revertir o que pueden implicar decisiones de vida o muerte, la decisión final no debería cederse a los sistemas de IA y debería ser adoptada siempre por un ser humano.

La Comisión Europea propone un enfoque orientado a la excelencia y la confianza basado en el nivel de riesgo que podría acarrear la IA, estableciendo 4 categorías y distintos niveles de control para cada uno, que van desde el «riesgo inaceptable», cuyas aplicaciones están prohibidas, pasando al «riesgo elevado», que requiere conformidad previa a su uso y controles periódicos internos y externos, hasta el «riesgo limitado» y «sin riesgo», que deben someterse a Códigos de Conducta Voluntarios ${ }^{4,5}$.

Finalmente, se retoman las palabras de Audrey Azoulay, directora general de la Unesco: «El mundo necesita reglas para que la inteligencia artificial beneficie a la humanidad» ${ }^{6}$.

\section{Referencias bibliográficas}

1. Bustamante A, Nikoletta B, Guillén Alonso ST. Un acercamiento al Big Data y su utilización en comunicación. Mediaciones Sociales 16(2017):115-134. 
2. Iglesias Rodríguez E, García Zaballos A, Puig Gabarró P, Benzaquén I. Inteligencia artificial: Gran oportunidad del siglo XXI: Documento de reflexión y propuesta de actuación del Banco Interamericano de Desarrollo (diciembre 2020). 132p. DOI: http://dx.doi. org/10.18235/0003037

3. Santaella, L. Inteligencia artificial y cultura: oportunidades y desafíos para el sur global. 2021. Recomendación sobre la Ética de la IA. Unesco. Disponible en: https://www.nic.br/media/docs/ publicacoes/8/20210429155702/policy paper inteligencia artificial y cultura ES.pdf

4. Europea Comisión. Libro Blanco sobre la inteligencia artificial: un enfoque europeo orientado a la excelencia y la confianza. Oficina de Publicaciones de la Unión Europea, 2020.
5. Núñez Zorrilla MC. Los nuevos avances en la regulación europea de la responsabilidad civil por los daños ocasionados en el ámbito del transporte con inteligencia artificial. REDE. 10 de noviembre de 2021;(78-79):201-56. Disponible en: http://revistasmarcialpons.es/ revistaespanoladerechoeuropeo/article/ view/636

6. Unesco. Audrey Azoulay: aprovechar al máximo la inteligencia artificial. Portal UNESCO. 2018. Disponible en: https:// es.unesco.org/courier/2018-3/audreyazoulay-aprovechar-al-maximo-inteligenciaartificial 